\title{
Instructors' justifications regarding curricular design: Assumptions about life sciences students and their role in physics courses
}

\author{
Mary K. Chessey ${ }^{1}$, Adrian M. Madsen², and Chandra A. Turpen ${ }^{1}$ \\ ${ }^{1}$ Department of Physics, University of Maryland College Park, 4150 Campus Dr, College Park, MD 20740 \\ ${ }^{2}$ American Association of Physics Teachers, 1 Physics Ellipse, College Park, MD 20740
}

To understand how physics faculty design and teach their Introductory Physics for Life Sciences (IPLS) courses, we analyzed interviews with faculty to learn about their ideas about their students. We focused specifically on the narratives faculty use to reason about their students as future professionals and how that related to their learning goals for such courses. We found that faculty reason about their students' needs when describing curricular design decisions in a range of ways, including with a strong sense of personal responsibility towards students' preparation, justification about what students have an interest in or will need in the future, and imagined relations between the faculty's self and professionals in the students' field of study. To better support physics faculty in teaching interdisciplinary physics courses, we aim to help faculty become more aware of their stances toward their students. This analysis suggests ways of broadening the narratives that faculty use to understand their life science students. 


\section{INTRODUCTORY PHYSICS FOR LIFE SCIENCES}

Many undergraduate physics major programs are densely-packed and highly-standardized in nature [1]. For many physics faculty, the undergraduate curriculum for physics majors goes unquestioned. At this time, however, the introductory physics curriculum for life science majors is being actively questioned and reconsidered. Professionals from other disciplines have called for a shift in priorities for the preparation of pre-medical, health sciences, and life sciences students [2-4]. These visions have resulted in substantive changes to major assessments for admittance to medical schools (i.e. the MCATs) [5], and have contributed to the changing landscape of introductory physics for life sciences (IPLS) echoing calls for students to have experiences "applying the concepts of chemistry and physics to situations that apply to the understanding of living systems" [Ref. 5, p. 173].

In response to these calls, physics faculty have developed multiple different innovative approaches to IPLS courses that reflect different prioritizations of stakeholders' needs and values [6-12]. However, there is little consensus on how these courses should be taught and what learning goals should be prioritized. For example, organizers of the recent 2014 IPLS conference report that there were, "vigorous discussions about what standard introductory physics topics might be eliminated or treated with significantly less detail than in the traditional introductory physics course... but all agreed that detailed decisions should lie with the individual instructor" [Ref. 13, p. 5]. The contested nature of the curriculum for such courses makes it a particularly interesting context for investigating faculty's reasoning about course design.

Other education scholars have described the moral, political and value-laden nature of education [14-15]. This means that fundamentally what is prioritized in IPLS course curricula is reflective of the values of course instructors and how they navigate the values of other stakeholders in society.

In this study, we investigate which and whose values are reflected in physics instructors' reasoning about what to prioritize in IPLS courses. Specifically, we ask: What justifications do physics faculty offer for what they prioritize in their IPLS curriculum?

\section{METHODS TO STUDY FACULTY REASONING}

\section{A. Data collection \& study sample}

As part of the larger Living Physics Portal project, we conducted semi-structured reflective interviews with 29 physics faculty teaching introductory physics for the life sciences (IPLS) in the US [16-17]. The purpose of these reflective interviews in part was to learn about: the variety of IPLS courses, faculty members' current pedagogical practices, how faculty perceive their course planning process and go about making sense of materials that were developed by others.

Of the original 29 interviews, we spoke with 13 faculty in remote video conferences and visited 16 faculty at their institutions. The styles of IPLS courses faculty were teaching varied significantly. Some of these courses followed the typical content outline for an introductory physics course and added some life science-relevant examples to the course. In others, the sequence and topics had been more drastically changed to align with the faculty member's understanding of what life science majors need.

For the preliminary analysis in this paper, we analyzed a subset of 14 interviews. These included 10 faculty from doctoral granting institutions, 1 from a bachelors granting institution and 3 from associates granting institutions. This sample includes faculty from across the US ( 5 West, 5 South, 3 Midwest, 1 Northeast). We perceived ten faculty as masculine and 4 as feminine, and the majority of faculty in this subset as white (12 out of 14). We plan to follow up with participants to self-report salient features of their identity.

Usually there were two interviewers talking to each faculty member. One interviewer took the primary role in asking questions and the other listened, took notes and chimed in with additional questions. The interviewers worked from a common protocol, but asked a variety of follow-up questions depending on what the participant talked about. The interview protocol listed questions for faculty about their course, students and course planning process including before the term starts and week-by-week during the term. Other interview questions about faculty's participation in online communities or in successful collaborations contributed to the design of the Living Physics Portal website, but not substantially to the current analysis [16].

\section{B. Qualitative analysis of interview data}

To understand the extent to which students influenced the participants' IPLS curriculum development, we searched the interview transcripts for instances where instructors talked about the students enrolled in their classes. Qualitative analysis software, NVivo 12 Pro, aided the transcript coding process. Initial development of codes entailed iterative analysis and discussion among all three authors about student themes in five transcripts. We reduced and clarified the code for "Students" (when instructors talked about students in their class), then two authors applied this code to two additional transcripts [18]. Estimates of interrater reliability on use of the "Students" code on the two new transcripts provided satisfactory results (87.2 and 89.9 percent agreement; kappa coefficients 0.73 and 0.75 ), then remaining transcripts were coded independently without discussion [19-20]. We coded 14 transcripts total; findings here represent only this 
preliminary work that is not generalizable beyond the subsample analyzed. Iterative discussion and review of the entire reduced dataset allowed authors to (A) list the variation and disagreement around what topics participants named that students should study, (B) explore participants' varying justifications for those decisions, and (C) identify students' influence relative to other stakeholders shared over those decisions.

Pragmatic concerns prompted analysis for faculty's statements about IPLS topics and justifications for their stances. Later, researcher values around centering students in the classroom and acknowledging historical patterns of unequal power between faculty and students made a sociopolitical lens useful for interpretation of findings [21-22]. Specifically, gathering evidence about who decides the curriculum is one measure of power that has been identified in mathematics education research, and which offers physics education researchers a useful tool for examining new IPLS classes [23-26].

\section{FINDINGS}

We found that when talking about their students, instructors shared (A) many ideas about what students should get out of their IPLS class, (B) varying justifications for why those outcomes are important for their students, and (C) that instructors drew from other faculty and printed resources more than from current (or past) students to decide how to connect the class with students' interests and needs.

\section{A. Faculty named topics, skills, and ways of thinking as what students need from IPLS courses}

When talking about their students, interviewees named topics to understand and skills to gain and described ways of thinking and communicating as desired outcomes of their students' participation in IPLS courses.

\section{Topics and skills to prioritize or avoid}

Valuable topics and skills for IPLS students included unit conversions, "how tendons can pull and move muscles," torque applied to the movement of the arm, how electromagnetic waves interact with biological systems, electricity and nerve conduction, voltage around neuroscience, waves focused on sound, electricity focusing on cell membranes as capacitors, mechanics in muscular structure, optics of the eye, physics of medical instruments like magnetic resonance, buoyancy, physical science topics on the MCAT, and technical skills in math, quantitative reasoning, critical thinking, and analysis. Aside from these important topics, faculty also specified topics and skills that are unimportant for life sciences students or that should be avoided, such as, "complicated details of a system of tendons," pulleys, cylinders rolling downhill, circular motion, projectile motion, relativity, optics, plugging numbers into calculators, and memorization. Notably, interviewees in our sample disagreed about the importance of torque, circular motion, and optics to life sciences students, consistent with earlier reports on faculty discussions about which topics to include in introductory physics for life sciences (IPLS) classes [13].

\section{Desired ways of thinking and communicating}

Faculty described ways of thinking and communicating as additional goals for IPLS students. For example, interviewees reported that students should "have the right learning approach for the [MCAT] that they need to take," use "simple models applicable to a wide range of phenomena," "see science as a unified whole," "think of problems in a particular manner unique to physics," develop habits of mind, use "logical reasoning that produces an answer," learn cooperatively, use "logical, physics-y thinking," practice "how you're putting together ideas and communicating them," and "describe these concepts using your own words but correct scientific language." One interviewee specified that the preferred problem-solving approach entails advance thinking followed by deliberate forward progress instead of trying many things without careful planning until one works. Two participants shared affective learning goals for their IPLS students. Bud (all interviewee names have been changed to pseudonyms) described being motivated to teach well enough that his students won't say, "I hated physics," in the future. Harley has another example of an affective goal, stating, "We also have to make them believe that it's important, and they can do it," which is why he connects concepts in class to "whatever [else] they're studying." Goals to change students' learning approaches, perspectives, and ways of thinking and communicating were important to some physics faculty in our sample, but progress towards these goals within IPLS courses and transferability of these skills by students to other contexts warrants further investigation beyond the scope of this study.

\section{B. Faculty provided varying justifications for their desired learning outcomes for their students}

Justifications for desired outcomes for their students included the following varieties: (1) explicit link to importance for the assumed future professions of particular majors, (2) explicit link to helping students succeed in IPLS classes, or (3) little to no justification.

\section{Justification based on assumed future professions}

In some cases, faculty's justification for the learning goal of the IPLS course was explicit and related to students' lives after completing the class. For example, Alton stated, "I'm all for unit conversions, especially for medical people," and 
specified that knowing, "the difference between a milligram and a microgram," is relevant to his students. Patricia explained, "I think that the reason you take this course is... because physicians realize that there's some set of skills that comes out of breaking up problems and working on a piece even if you can't see what the end point is. There's an analytic process there that's going to help you become a better diagnostician." Harley related, "I think it's important, again because of my personal experiences, and the idea of being at a doctor's, and this doctor saying, 'Well, we're going to use magnetic resonance to be able to study something,' ... So to me, the doctors... are going to really need to be more technically adept." Harley chose to emphasize technical knowledge with IPLS students because he viewed them as future doctors who would need to interpret magnetic resonance imaging data. Blake explained, "I also try to sell them on the idea that it's not just that you're going to be, you know calculating forces in your future career because you probably won't be but on that problem solving aspect... That is huge to me." Blake clearly distinguished some activities in the class, like "calculating forces", from what will be needed in students' careers, but justified them as contributing to the goal of improving "analysis abilities." Bud explained, "I tell ... doctors and nurses... I say, 'I teach physics.' They go, 'I hated physics.' So... I wanted to teach physics well so that at least some people wouldn't say that." One of Bud's big learning goals in his IPLS course is to positively influence the attitudes of future doctors and nurses, who he assumes are his students, about physics. In each of these cases, the faculty's justification relates to the assumed future profession of the students in the class.

\section{Justification based on assumed interests of students to encourage high in-class engagement}

Interviewed faculty justified what was important in IPLS courses by focusing on what would help students engage and succeed while they are in the class. Sinclair, who recently started teaching the IPLS course under the mentorship of a prior instructor shared that, "He was saying what we should be teaching doctors about things related to biosciences and medicine and not about pulleys and cylinders rolling downhill; they don't seem to care about that." Here, students' "care" about topics in the class helped them to engage more actively with interesting materials. Greta described changing the IPLS course over time to better engage students in the class: "As the majority of students have a major that is related to life sciences, we hope that we can get more attention from them to those physics concepts by relating the material to life science topics." In these two examples, the justification for the topic in the class was to relate to students' inferred interests given by their majors in order to increase engagement and attention from students in the class. Another example shows justification for omitting something in a textbook from class because it may discourage students. Alton says, "There is one example... that's like, 'Here's how this system of tendons works.' And you're like, 'No. No, they don't need to see that'... It can make them discouraged because like, 'Should I know how to do this?' There's nowhere in here that I, or the book, have taught them how to do that." Alton assumed that overly complicated examples from a textbook would have the undesirable effect of discouraging students.

\section{Unspecified justification during the interview}

Some participants made claims about what was important for students in IPLS classes, but little to no justification supported the claim in the interview. Neil explained that he taught, "Waves focused on sound because I have audiology students..." Here Neil connected his students' major and intended profession to a topic he included in his class, but didn't explicitly justify why he believed that these students needed to learn about this topic. For instance, what about the study of sound as waves most matters to audiology students and why? Neil also explained that he met with faculty from a health professions department to discuss the topics he includes in his course. "One of the things I discovered, optics is out. Don't do optics, but some other things like for example, understanding voltage around neuroscience is important. Mechanics in muscular structure is important." Here Neil relied on the recommendations of health professionals for why topics should be included or not included, but did not elaborate further on why this was a sensible way to make decisions that impacted the students in his class. There may have been an assumption that health professions faculty members' expert opinions on what the life sciences students should learn in physics hold high value for students. As another example where little clear justification was provided in the interview, Dan explained, "My philosophy though is that if it's not relevant, it should not be taught." Later he talked about his course planning process, and how he looks at each topic he is planning to teach, stating, "...you move on to each topic and I try to answer the question, as much as possible, 'Why is this important? Why are we teaching this?' " Dan was very thoughtful about choosing topics for his course, but he did not explain in the interview how he personally knew which topics were relevant to current students. His description suggested an independent judgement call. Duncan also talked about what he includes in his course, justifying his choices based on the majors of the students in his course, but didn't explain beyond that. $\mathrm{He}$ said, "I'm going to do waves, which I just think is more applicable to engineers than buoyancy, and buoyancy, I think, is really important for life science majors." In this example, it was unclear from the interview why Duncan believed that buoyancy was more important than waves to life science majors. In each of these cases, unspecified justifications may 
only suggest places where interviewees assumed a shared understanding with researchers and did not expand further than seemed necessary during the interview.

\section{Faculty developed these ideas primarily independently from students taking the class}

In this section we argue that instructors emphasized priorities for student learning outcomes in IPLS classes that were primarily informed by non-student sources. Instructors in our sample reported picking up course materials and goals from other faculty, especially previous instructors of the class at their institution. For example, Padmini describes using a manuscript and modules developed as part of a colleague's grant project. Bud also got materials from a colleague who developed them at his institution. At times, these peer-to-peer faculty discussions conveyed assumptions about what could be reasonably expected of "this" student population. Another faculty, Neil, shares that he "talked to the previous year's faculty [about] what the students are willing to do and what they're not willing to do and where they can go with that."

Physics faculty also cited local life sciences faculty or medical professionals as influencing their prioritization of learning outcomes and course content. For example, Padmini says, "All the time. I collaborated [with a retired radiologist]... she proofreads our stuff... She knows all the medical part, and so she was proofreading my stuff and I just did physics." Harley reported talking frequently with a faculty member from biology while he learned about biology examples to use in his IPLS class. Clearly, health, medical, and life sciences faculty and professionals influenced curricular choices of physics instructors in our study.

Discussion with other faculty was the primary source of information about what is "important" or "relevant" to students, mentioned by 13 out of 14 interviewees in our sample. One participant reported that the Vision \& Change Report, published by the AAAS, weighed on the desired student outcomes of his IPLS course. Two other participants described referring to biology or physiology textbooks for developing materials for their IPLS students.

Fewer participants described students as influencing IPLS curriculum or learning goals. In two cases, instructors said that they directly invited students to share their interest areas, one outside of class time at optional discussions (Bruce) and one during class time (Bud). In these cases, the faculty intentionally shaped the course around current student interests and concurrent studies in students' life sciences classes. Bruce reported using students' ideas for examples in the class for future academic terms, and only from the subset of students with whom he had personal interactions outside of scheduled class or office hours time.

Three others reported attention to current students' needs and concurrent disciplinary studies (Billy, Harley and Greta), but it wasn't clear how these instructors established that knowledge. For example, Harley connects concepts in the IPLS class to "whatever they're studying," but it's not clear from the interview what else students are learning or how Harley knows this information. Most interviews that we analyzed ( 9 out of 14) contained no evidence that the instructor relied on current student input during course planning throughout the academic term.

Exploration of our sample of interviews provided strong evidence that IPLS instructors rely on other faculty to determine learning outcomes for students, but little evidence suggested that current students have much "voice in the classroom" in terms of deciding IPLS curriculum in most cases in this sample [22-24].

\section{LIMITATIONS}

Interviews captured instructors' reports on course planning and class time, but not direct observations, which may differ. Further, we described unspecified justifications and the relatively small presence of student voice in course planning, but the interview protocol did not specifically emphasize probing for details about these points. As such, our claim that other faculty had a greater influence than current students had on curriculum is limited to the aspects of course planning that interviewees felt most relevant to share. Finally, our preliminary analysis relied on a reduced dataset focused on moments related to students, omitting parts of interviews that we deemed more relevant to the design of the Living Physics Portal [16].

\section{DISCUSSION AND CONCLUSIONS}

We found that faculty relied primarily on assumptions about students' interests and future professions, and on other faculty to justify their curricular choices. A significant opportunity exists to improve equity in IPLS classes by inviting students' voices in the classroom to shape the direction of the class each term [22]. Our finding about the contested nature of choosing topics to appear in an IPLS course (torque, circular motion, optics), aligns with prior documentation of physics faculty's vigorous discussions around these classes [13], and reveals some of physics instructors' values [14-15]. We invite faculty to maintain adaptability within IPLS classes and to draw more from current students to make curricular design decisions [27-29].

\section{ACKNOWLEDGMENTS}

We thank the faculty members who participated in interviews. We appreciate Stephanie Williams' and reviewers' constructive feedback on an earlier draft of this paper, and Sam McKagan and Remy Dou's contributions to data collection efforts. This work is supported by NSF-DUE 1624478 and 1624185. 
[1] J. Nespor, Knowledge in Motion: Space, Time and Curriculum in Undergraduate Physics and Management. (Falmer, Philadelphia, 1994).

[2] AAAS, Vision and Change in Undergraduate Biology Education: A call to action. (AAAS, 2011).

[3] AAMC/HHMI, Scientific Foundations for Future Physicians (AAMC/HHMI, 2009).

[4] Committee on Biology Education, Bio2010: Transforming undergraduate education for future research biologists. (National Academies Press, Washington, DC., 2003).

[5] R. C. Hilborn and M. J. Friedlander, "Biology and physics competencies for pre-health and other life sciences students." CBE Life Sci. Educ. 12(2), (2013).

[6] E. F. Redish and D. Hammer, "Reinventing College Physics for Biologists: Explicating an Epistemological Curriculum," American Journal of Physics 77, 629-642 (2009).

[7] J. Watkins, J. E. Coffey, E. F. Redish, and T. J. Cooke, "Disciplinary Authenticity: Enriching the reform of introductory physics courses for life science students," Physical Review Special Topics - Physics Education Research 8010112 (2012).

[8] D. C. Meredith and E. F. Redish, "Reinventing physics for life science majors," Physics Today 66:7, 38-43 (2013).

[9] W. Christensen, J. K. Johnson, G. R. Van Ness, E. Mylott, J. C. Dunlap, E. A. Anderson, and R. Widenhorn, "Developing and Assessing Curriculum on the Physics of Medical Instruments," CBE Life Sci. Educ. 12(2):250-61 (2013).

[10] E. F. Redish, C. Bauer, K. L. Carleton, T. J. Cooke, M. Cooper, C. H. Crouch, B. W. Dreyfus, B. Geller, J. Giannini, J. Svoboda Gouvea, M. W. Klymkowsky, W. Losert, K. Moore, J. Presson, V. Sawtelle, K. V. Thompson, C. Turpen, and R. Zia, "NEXUS/Physics: An interdisciplinary repurposing of physics for biologists," American Journal of Physics 85:5, 368-377 (2014).

[11] B. Geller, C. Turpen and C. Crouch, "Sources of student engagement in Introductory Physics for Life Sciences." Physical Review - Physics Education Research, 14, 010118 (2018).

[12] N. Donaldson, L. K. Felzien, M. C. Marvin, J. J. Cielocha, and T. Shapiro, "Development of an interdisciplinary conceptual conservation of energy theme for use in undergraduate physics, chemistry, and biology courses." American Journal of Physics, 87(527), (2019).

[13] AAPT, 2014 Conference on Introductory Physics for the Life Sciences Report (AAPT, College Park, MD, 2015). Available at: https://www.compadre.org/IPLS/documents/IPLS-Final-Report. pdf

[14] D. F. Labaree, "Public Goods, Private Goods: The American Struggle over Educational Goals." American Educational Research Journal, 34(1), (1997).

[15] G. Biesta, "Why 'what works' won't work: Evidence-based practice and the democratic deficit in educational research." Educational Theory, 57(1), (2007).

[16] https:/www.livingphysicsportal.org/

[17] A. Olmstead and C. Turpen, "'Curriculum swaps' as a pathway into a geographically-distributed instructional community." 2018 Physics Education Research Conference Proceedings [Washington, DC, August 1-2, 2018].
[18] M. B. Miles and A. M. Huberman, "Qualitative data analysis: An expanded sourcebook," (Sage, Thousand Oaks, CA 1994).

[19] J. Cohen, "A coefficient of agreement for nominal scales," Educational and Psychological Measurement 20:1, 37-46 (1960).

[20] M. L. McHugh, "Interrater reliability: The kappa statistic," Biochem Med (Zagreb) 22:3, 276-282 (2012).

[21] N. S. Nasir and M. McKinney de Royston, "Power, identity, and mathematical practices outside and inside school," Journal for Research in Mathematics Education 44:1, 264-287 (2013).

[22] R. Gutiérrez, "Context matters: Equity, success, and the future of mathematics education," in 29th Annual Conference of the North American Chapter of the International Group for the Psychology of Mathematics Education Proceedings, Stateline, $N V, 2007$, edited by T. Lamberg and L. R. Wiest (University of Nevada, Reno, 2007), p. 1-18.

[23] H. Morales, "The underlife of a high school mathematics classroom: Mathematical meaning-making among Latino/a students," A paper presented at the annual meeting of the American Educational Research Association (2007).

[24] R. Zevenbergen, "Cracking the code of mathematics classrooms: School success as a function of linguistic, social, and cultural background," in Multiple Perspectives on Mathematics Teaching and Learning, edited by J. Boaler 201-223 (2000).

[25] J. Adler, "A language of teaching dilemmas: Unlocking the complex multilingual mathematics classroom," For the Learning of Mathematics 18:1, 24-33 (1998).

[26] S. A. Gregson, "Negotiating social justice teaching: One full-time teacher's practice viewed from the trenches," Journal for Research in Mathematics Education 44:1, 164-198 (2013).

[27] H. Jardine and L. Friedman, "Using Undergraduate Facilitators for Active Learning in Organic Chemistry: A Preparation Course and Outcomes of the Experience," Journal of Chemical Education, 94:6 (2017).

[28] M. S. Sabella, A. G. Van Duzor, and F. Davenport, "Leveraging the expertise of the urban STEM students in developing an effective LA Program: LA and Instructor Partnerships." 2016 Physics Education Research Conference Proceedings [Sacramento, CA, July 20-21, 2016].

[29] K. Tobin, "Learning to Teach Through Coteaching and Cogenerative Dialogue," Teaching Education, 17, 133-142 (2006). 